\title{
Ventilators for Noninvasive Ventilation in Adult Acute Care
}

\author{
J Brady Scott
}

\author{
Introduction \\ NIV Versus CPAP \\ NIV Terminology \\ NIV Technology \\ Bi-Level Ventilators \\ Critical Care Ventilators \\ Intermediate Ventilators \\ Review and Evolution of the Literature Comparing Devices \\ Clinical Considerations \\ Types of Ventilation \\ Modes \\ Leak Compensation \\ Trigger/Cycle \\ Monitoring Capabilities, Portability, Cost, and Familiarity \\ Summary
}

\begin{abstract}
The use of noninvasive ventilation (NIV) is common in adult acute care. As evidence to support the use of NIV has developed, there has been a concurrent proliferation of NIV technology. Efforts have been made to improve patient-ventilator synchrony, monitoring capabilities, and portability of devices used to deliver NIV. The technological enhancements provide clinicians with myriad modes, settings, and capabilities designed to improve patient adherence with NIV. Although this technology is generally superior to that of the past, a great deal of variation exists between devices. Clinicians need to be accustomed to the devices available to them to maximize the potential for clinical improvement and patient tolerance. The purpose of this paper is to review current technology, current literature comparing devices, and various clinical considerations associated with NIV use in adult acute care. Key words: noninvasive ventilation; acute respiratory failure; noninvasive ventilator; bi-level; ventilator; mechanical ventilation; NIV. [Respir Care 2019;64(6):712-722. (C) 2019 Daedalus Enterprises]
\end{abstract}

\section{Introduction}

Noninvasive ventilation (NIV) is a common modality used to treat acute respiratory failure in adult patients. ${ }^{1}$

\footnotetext{
Mr Scott is affiliated with Rush University, Department of Cardiopulmonary Sciences, Division of Respiratory Care, Chicago, Illinois.

Mr Scott has disclosed a relationship with Ventec Life Systems.

Mr Scott presented a version of this paper at the 57th RESPIRATORY CARE Journal Conference, held June 14-15, 2018, in St Petersburg, Florida.
}

The evidence supporting the use of NIV in various disease processes, such as acute cardiogenic pulmonary edema and exacerbations of COPD, is strong. ${ }^{1,2}$ Many studies have examined outcomes in terms of cost, morbidity, and mortality associated with the use of NIV, but the focus has

\footnotetext{
Correspondence: J Brady Scott MSc RRT RRT-ACCS AE-C FAARC, Rush University Department of Cardiopulmonary Sciences, Division of Respiratory Care, Armour Academic Center, 600 S. Paulina, 751 AAC, Chicago, IL 60612. E-mail: jonathan_b_scott@rush.edu.
}

DOI: $10.4187 /$ respcare. 06652 
Table 1. Ventilator Terminology and Clinical Changes

\begin{tabular}{lll}
\hline \hline \multicolumn{1}{c}{ Setting } & Change & Clinical Changes \\
\hline IPAP/Pressure Support & Increase & Increase tidal volume, increased ventilation/decreased $\mathrm{P}_{\mathrm{aCO}}$ \\
IPAP/Pressure Support & Decrease & Decrease tidal volume, decreased ventilation/increased $\mathrm{P}_{\mathrm{aCO}}$ \\
EPAP/PEEP & Increase & $\begin{array}{c}\text { Increased } \mathrm{P}_{\mathrm{aO}} \text {, decreased tidal volume (on bi-level ventilator); } \\
\text { improve triggering if air-trapping is present }\end{array}$ \\
EPAP/PEEP & Decreased $\mathrm{P}_{\mathrm{aO}}$, increased tidal volume (on bi-level ventilator) \\
$\mathrm{F}_{\mathrm{IO}_{2}}$ & Decrease & Increased $\mathrm{P}_{\mathrm{aO}_{2}}, \mathrm{~S}_{\mathrm{aO}_{2}}, \mathrm{~S}_{\mathrm{pO}_{2}}$ \\
$\mathrm{~F}_{\mathrm{IO}_{2}}$ & Increase & Decreased $\mathrm{P}_{\mathrm{aO}_{2}}, \mathrm{~S}_{\mathrm{aO}_{2}}, \mathrm{~S}_{\mathrm{pO}_{2}}$ \\
$\mathrm{IPAP}=$ inspiratory positive airway pressure $_{\text {EPAP }=\text { expiratory positive airway pressure }}$ & Decrease & \\
Adapted from Reference 5. & & \\
\hline
\end{tabular}

primarily been on disease processes. ${ }^{1,2}$ It is likely that equipment used to provide NIV, such as ventilators, plays a role in the overall success or failure of NIV. 3,4

Early devices used for NIV utilized volume-targeted modes to deliver positive pressure. ${ }^{3}$ While helpful, these devices had profound limitations, namely, little or no ability to compensate for leaks, lack of an internal oxygen blender, and limited monitoring capabilities. ${ }^{1,3,4}$ The absence of leak compensation alone has been associated with NIV failure due to patient-ventilator asynchronies, such as trigger and cycle asynchrony. ${ }^{3}$ The lack of internal oxygen blenders made it hard to achieve desired $\mathrm{F}_{\mathrm{IO}_{2}}$, while the lack of proper monitoring capabilities posed a potential patient safety risk.

As the literature support for NIV has evolved, so has the technology. Modern NIV support devices now have clinical features designed to improve the likelihood of NIV success. The purpose of this paper is to review current technology and various clinical considerations associated with NIV use in adult acute care.

\section{NIV Versus CPAP}

NIV differs from CPAP in that NIV provides 2 levels of pressures. During NIV, pressure increases during the inspiratory phase of the breath and returns to an elevated baseline during exhalation. The pressure increase during the inspiratory phase augments tidal volume, thus improving gas exchange and unloading respiratory muscles. ${ }^{1,3}$ During CPAP, pressures are elevated above atmospheric pressure but remain constant throughout both the inspiratory and expiratory cycle of a breath. CPAP increases functional residual capacity and mean airway pressure, but does not unload inspiratory muscles like NIV.

\section{NIV Terminology}

Terminology associated with the pressures in NIV is not uniform and may vary from device to device. During the inspiratory phase of the breath, the pressure setting is com- monly termed inspiratory positive airway pressure (IPAP). IPAP is common terminology used to describe a setting on devices specifically designed to deliver NIV, and it is similar to pressure support on a critical care ventilator. During expiration, the pressure setting on devices designed primarily for NIV is termed expiratory positive airway pressure (EPAP). EPAP is similar to PEEP on a critical care ventilator.

Understanding the differences in device terminology is clinically important (Table 1). For example, the setting of $10 \mathrm{~cm} \mathrm{H}_{2} \mathrm{O}$ of IPAP and $5 \mathrm{~cm} \mathrm{H}_{2} \mathrm{O}$ of EPAP on NIV devices results in a pressure support level of $5 \mathrm{~cm} \mathrm{H}_{2} \mathrm{O} .{ }^{6}$ The peak inspiratory pressure in this case is $10 \mathrm{~cm} \mathrm{H}_{2} \mathrm{O}$. On a critical care ventilator, $10 \mathrm{~cm}_{2} \mathrm{O}$ of pressure support and $5 \mathrm{~cm} \mathrm{H}_{2} \mathrm{O}$ of PEEP results in a peak inspiratory pressure of $15 \mathrm{~cm} \mathrm{H}_{2} \mathrm{O}$ (Fig. 1). In this example, the inspiratory support from the critical care ventilator would be $5 \mathrm{~cm} \mathrm{H}_{2} \mathrm{O}$ more than the NIV device.

\section{NIV Technology}

There have been many attempts to classify devices utilized to deliver noninvasive ventilatory support; however, the terminology is varied, and there is no consensus agreement in the literature. Scala and $\mathrm{Naldi}^{3}$ classified these ventilators into 3 categories: bi-level ventilators, intermediate ventilators, and ICU ventilators (referred to as critical care ventilators in this paper). This is similar to other attempts in the literature and textbooks related to respiratory and critical care medicine. ${ }^{6-8}$ The 3 categories attempt to place these devices into groups that define their commonalities, like circuit configurations (Fig. 2). For example, bi-level ventilators have a single-limb configuration with a leak port, whereas critical care ventilators have dual-limb circuits with an expiratory valve, and intermediate ventilators may have either configuration. ${ }^{1}$ Due to the advancements in technology over the last 20 years, it is becoming increasingly more difficult to clearly discern one device category from the other. Bi-level ventilators, originally designed specifically for NIV, now have modes 


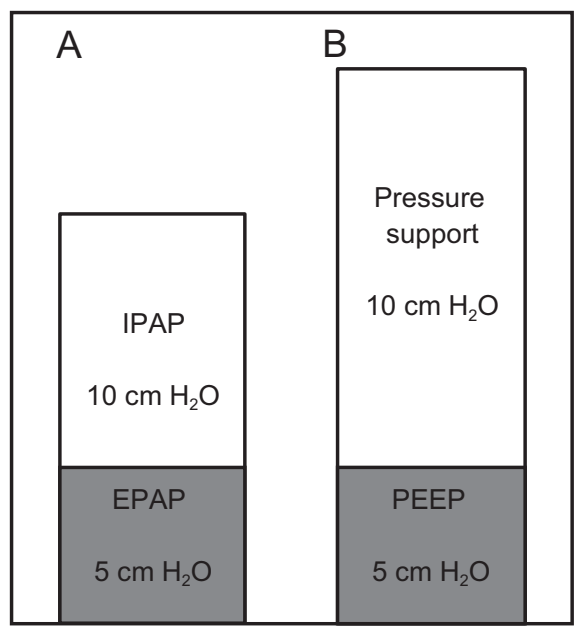

Fig. 1. A: Example of bi-level ventilator settings: peak inspiratory pressure $10 \mathrm{~cm} \mathrm{H}_{2} \mathrm{O}$ and pressure support $5 \mathrm{~cm} \mathrm{H} \mathrm{H}_{2} \mathrm{O}$. B: Example of critical care ventilator settings: peak inspiratory pressure $15 \mathrm{~cm} \mathrm{H}_{2} \mathrm{O}$ and pressure support $10 \mathrm{~cm} \mathrm{H}_{2} \mathrm{O}$. IPAP = inspiratory positive airway pressure, EPAP = expiratory positive airway pressure. From Reference 5.
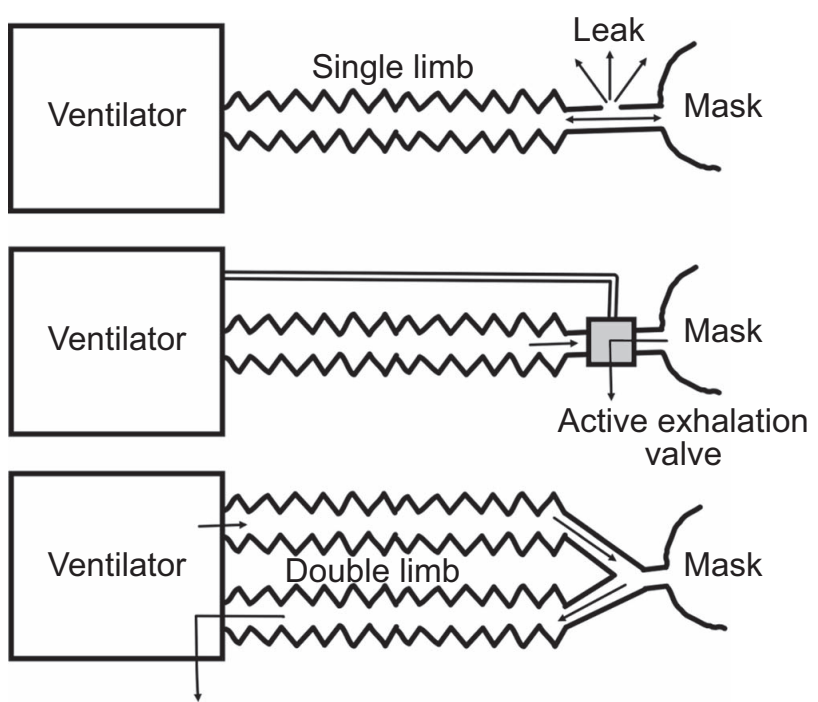

Fig. 2. Circuit configurations for noninvasive ventilation. From Reference 1.

capable of delivering positive pressure invasively. Conversely, critical care ventilators, originally designed for invasive mechanical ventilation, now have modes capable of delivering positive pressure noninvasively. Intermediate ventilators, used primarily for transport and home care, also have the ability to support patients invasively and noninvasively.

\section{Bi-Level Ventilators}

Bi-level ventilators are configured with a single-limbed circuit and are designed to operate in the presence of a leak. Due to the absence of an expiratory valve, the leak serves to flush the circuit of exhaled gases through a leak port located either in the circuit or the interface. This flushing of the circuit reduces the likelihood of rebreathing carbon dioxide that can accumulate within the interface or the circuit. ${ }^{9}$

The potential for rebreathing in a single-limbed circuit is particularly high in the presence of a high minute volume. When patients exhale more than the capacity of the leak port to flush the system, rebreathing can occur. ${ }^{1,6}$ The risk of rebreathing can be mitigated by elevating the baseline expiratory pressure, using a plateau exhalation valve, and leak port placement in the mask. ${ }^{6,10}$ In some bi-level ventilators, expiratory pressure cannot be set $<3$ or $<4 \mathrm{~cm} \mathrm{H}_{2} \mathrm{O}$ to assure that the circuit is adequately flushed. The newest generation of bi-level ventilators allows the user to input the interface being used during NIV. This feature allows the device to identify intentional versus unintentional leaks so that the flow can be adjusted to maintain desired performance. ${ }^{1,6} \mathrm{Bi}$-level ventilators, due to the lack of a dedicated exhalation limb, require interfaces with anti-asphyxiation valves in the event of device failure. This allows the patient to breathe fresh gas until the mask is removed or the device failure is resolved.

Like their critical care counterpart, modern bi-level ventilators have several modes, numeric monitoring displays, scalar graphics, alarm parameters, and internal oxygen blenders. ${ }^{4}$ Estimates of tidal volume and leak are made through algorithms specific to the device. Although the accuracy of these algorithms has not been well studied, these devices have been reported to work properly in the presence of leaks.

The amount of acceptable leak that each device can tolerate is not known. What is known is that a significant leak can result in improper device function, such improper trigger or cycle. Thus, it stands to reason that leaks that result in trigger or cycle asynchrony are unacceptable.

Bi-level devices may be equipped with internal or external battery sources that allow for intra-hospital transport. Some bi-level ventilators can provide ventilatory support through endotracheal and tracheostomy tubes.

\section{Critical Care Ventilators}

As mentioned previously, critical care ventilators were originally designed to deliver invasive positive pressure. The circuit on a modern critical care ventilator is duallimbed, with an inspiratory and expiratory limb. The risk of rebreathing exhaled gases is less because of the expiratory limb and valve.

Critical care ventilators were historically very poor at providing NIV. ${ }^{3}$ The newer generation of these devices are now equipped with modes specifically designed to be used for the application of NIV. These modes are not unique per se, but they permit the mechanical ventilator to automat- 
ically compensate for leaks. These NIV modes may also deactivate some alarm parameters that are unnecessary and even problematic. ${ }^{4}$ Critical care ventilators, because of their active expiratory valve, do not require an anti-asphyxiation valve in the interface. With that said, it is incumbent upon the clinician to properly set device alarms to detect any malfunctions.

\section{Intermediate Ventilators}

Intermediate ventilators are most often associated in the literature with transport and home use. These devices may have single or dual-limbed circuit configurations; singlelimbed circuits have either an active exhalation valve near the patient or a passive leak similar to bi-level devices. Current intermediate ventilators have various modes that are pressure- or volume-targeted. Some devices may also be equipped with specialty modes like average volumeassured pressure support (AVAPS, Philips Respironics, Murrysville, PA) and intelligent volume-assured pressure support (iVAPS, ResMed, San Diego, CA). ${ }^{6}$

\section{Review and Evolution of the Literature Comparing Devices}

There have been many attempts to better understand how ventilators perform while delivering positive pressure via a noninvasive interface. These studies have evaluated different technical aspects of NIV device performance, including trigger performance, rate of pressurization in pressure-targeted modes, response to system leaks/leak compensation, performance of device algorithms, patientventilator asynchrony, and interface-device performance. ${ }^{11}$

In 2007, Vignaux et al ${ }^{12}$ tested 8 critical care ventilators, commonly available at the time, using a bench model. Their model used a plastic head to mimic a spontaneously breathing patient on NIV. Parameters associated with the pressure support mode of ventilation were evaluated in the presence and absence of leak such as triggering, pressurization, and inspiratory:expiratory cycling. Despite several admitted limitations to their study, they noted that leaks interfered with many key critical care ventilator functions, such as increased trigger delay, decreased pressurization, and cycle delay. NIV-specific modes partly or totally alleviated the issues associated with leaks, but there was a wide degree of variability among devices. ${ }^{12}$

In a review article in 2008, Scala and $\mathrm{Naldi}^{3}$ noted that clinicians should understand NIV device performance because patient-ventilator asynchrony and discomfort could be a result of inadequate settings. Upon their review of the available literature at the time, they noted that devices specifically designed for NIV and critical care ventilators with NIV modes offer advantages over their predecessors. Bi-level ventilators demonstrated comparable performance capabilities with regard to trigger, pressurization rate, inspiratory work, cycling, and response to ventilatory demands when compared to critical care ventilators. Newer critical care ventilators with NIV modes had superior performance to older critical care ventilators in bench studies. $^{3}$

In a 2009 bench study, Ferreira et al ${ }^{13}$ compared the performance of 9 critical care ventilators to a bi-level ventilator in the presence of leaks. The authors noted that as leak increased, all ventilators except one critical care ventilator and the studied bi-level ventilator required parameter adjustment to maintain synchrony. During this sequential leak increase, some ventilators transitioned to backup ventilation. They noted that all of the studied ventilators could deliver NIV in the setting of low-level leaks.

In 2010, Vignaux et $\mathrm{al}^{14}$ evaluated the impact of NIV algorithms on patients on critical care ventilators receiving NIV for acute respiratory failure. In this prospective, randomized, crossover study conducted in 3 different university hospitals, the study team measured various parameters with the NIV mode on and OFF, each for 30 min, respectively. They found that the asynchrony index (ie, the ratio of the number of asynchrony events divided by total breathing frequency) was not different between the ON and OFF groups. However, they did note that auto-trigger was lower and there were fewer ineffective efforts with the NIV mode ON. The NIV algorithm was also associated with a decrease in late cycling. The study authors concluded that NIV algorithms were helpful in decreasing some asynchronies caused by leaks, but the algorithms did not necessarily eliminate asynchronies overall. They also noted that these results could be due to the varying approaches manufacturers have toward improving patient-ventilator asynchrony. ${ }^{14}$

Carteaux et al ${ }^{15}$ conducted both a bench study and a clinical study to evaluate patient-ventilator asynchrony during NIV. During the bench study, they assessed the impact of inspiratory and expiratory leaks on cycling and triggering on 19 different ventilators. The ventilators included in the study consisted of critical care ventilators, transport ventilators, and dedicated NIV ventilators. They found that dedicated NIV ventilators outperformed other devices in terms of patient-ventilator asynchrony. The authors noted that this was the case even when NIV algorithms in the critical care ventilators were on. They also reported that critical care and transport ventilator NIV algorithms behaved differently in terms of patient-ventilator synchronization in the presence of leaks. Because of this, they suggested that device capabilities should be considered individually. Also, the asynchrony index was lower with NIV dedicated ventilators compared to critical care ventilators with NIV algorithms ON or OFF. The authors concluded that, even though critical care and transport ventilator NIV algorithms do improve synchronization, NIV 
dedicated ventilators outperformed critical care ventilators. ${ }^{15}$

Using a lung simulator, Oto et al ${ }^{16}$ evaluated the impact of system leaks on 7 critical care ventilators and 1 bi-level ventilator. The lung simulator was set to mimic a patient with ARDS and COPD. All ventilators were compared during increasing and decreasing system leaks. They found that 3 critical care ventilators in NIV mode and the bi-level ventilator synchronized to all leaks in both the ARDS and COPD model. Only the bi-level ventilator and 1 critical care ventilator maintained synchrony in all leak scenarios without adjustment of trigger and cycle criteria. They concluded that leak, lung mechanics, and PEEP influence ventilator performance. Like Scala and Naldi, ${ }^{3}$ the authors noted that clinicians should be aware of variables that impact ventilator performance.

In 2014, Nakamura et al ${ }^{17}$ sought to determine whether critical care ventilators were able to compensate for large leaks associated with some models of total face mask NIV interfaces. During this bench study, 8 critical care ventilators and 1 bi-level device were tested. All devices were tested at 2 levels of PEEP and at 3 levels of pressure support. Of the 8 critical care ventilators, 4 were considered nonoperational due to device interpretation of disconnection and auto-triggering. Only 1 critical care ventilator and the bi-level ventilator worked properly in the setting of large leaks. In the absence of leaks, all ventilators performed adequately. The authors concluded that most critical care ventilators were unable to deliver NIV with total face mask interfaces because of the large leak. ${ }^{17}$

In bench and clinical studies to date, bi-level ventilators have generally outperformed critical care ventilators in the presence of leaks. It should be noted, however, that these studies have shown that some critical care ventilators perform well and comparatively to bi-level ventilators under these circumstances. This underscores 2 very important points: First, devices capable of delivering NIV should be evaluated individually, not as a group, because their capabilities are manufacturer specific. Second, individuals responsible for initiating and managing NIV should be well-trained on the nuances that exist between devices.

In addition, some newer critical care ventilators have not yet been evaluated. It is possible that further technological advances have improved equipment performance, but this cannot be assumed. More bench and clinical studies are warranted to inform clinicians how to achieve top performance of their device and to drive purchasing decisions. Although bench studies serve a purpose, we must use caution in interpreting their results. Olivieri et al ${ }^{18}$ noted that several bench studies have had inconsistent and even conflicting results. They suggest a more standardized approach to experimental settings and measurement criteria to improve the interpretation of results from bench studies. Further, they add that a more uniform terminology regarding NIV is needed.

Moving forward, larger clinical studies that compare critical care ventilators to bi-level ventilators are needed help us understand if a true clinical benefit of one versus the other exists. This would be challenging and complicated by variables such as NIV interface, disease process, and severity of illness, which would make the results difficult to interpret. ${ }^{3}$ Until we better understand whether a true difference exists between devices, clinicians will have to choose devices based on types of ventilation needed (invasive vs noninvasive), modes, leak-compensation abilities, trigger/cycle settings, monitoring capabilities, portability, cost, and familiarity with the device. ${ }^{1}$

\section{Clinical Considerations}

\section{Types of Ventilation}

Categorizing bi-level, critical care, and intermediate ventilators is becoming more challenging because they all possess similar abilities. Bi-level ventilators now have the ability to provide invasive mechanical ventilatory support, as do intermediate ventilators. Some critical care ventilators can provide effective noninvasive ventilatory support, similar to the intermediate and bi-level ventilators. All 3 categories of devices may be capable of use during transport, although devices designed with internal compressors (eg, turbine or piston) may be better suited for this application. Clinicians may need to decide whether the modes and leak-compensation abilities of the device they are choosing are suitable for the clinical need. If the patient's condition is complex and requires advanced ventilatory support and monitoring, critical care ventilators may be advantageous. If leaks are prevalent, bi-level ventilators may be advantageous.

\section{Modes}

Mode terminology may vary between devices, but pressure support is the most common mode in NIV. ${ }^{1}$ Pressure support allows the patient to have variability in inspiratory time and flow, which may improve patient-ventilatory synchrony. Set inspiratory times, like in pressure control modes, may result in cycle asynchrony. As mentioned previously, clinicians need to understand the behavior of pressure support and PEEP on their devices because these may differ between critical care, bi-level, and intermediate ventilators.

On bi-level devices, a common mode is spontaneous/timed $(\mathrm{S} / \mathrm{T})$. This mode allows patients to breathe spontaneously, with a backup rate set for safety. During mode activation, the IPAP, EPAP, breathing frequency, inspiratory time, rise time, and oxygen settings are input by the clinician. 
When a patient triggers a breath spontaneously, these devices use internal trigger and cycle algorithms to start and stop the breath. If the patient fails to trigger a breath above the set time interval (determined by the frequency) the device will trigger a breath. In this case, the breath will cycle by the set inspiratory time. The set inspiratory time is only activated during a device-triggered breath.

Other modes such as AVAPS, neurally-adjusted ventilatory assist (NAVA), and proportional assist ventilation (PAV) have also been used to provide NIV. In AVAPS, the level of pressure support adapts to deliver an average tidal volume. This is a form of volume-targeted adaptive pressure control. The clinician sets tidal volume, minimum/maximum inspiratory pressures, baseline pressure (EPAP), $\mathrm{F}_{\mathrm{IO}_{2}}$, breathing frequency, and rise time.

In 2017, Ciftci et al ${ }^{19}$ evaluated the use of AVAPS in COPD subjects with acute hypercapnic respiratory failure. They placed 106 subjects with COPD on AVAPS and found that $81(76.4 \%)$ of them were successfully treated. The failure group included subjects who subsequently required invasive mechanical ventilation or died after being initially placed on AVAPS. It should be noted that the AVAPS failure group had a lower mean $\mathrm{pH}(7.26 \pm 0.02)$ and a lower $\mathrm{P}_{\mathrm{aO}_{2}} / \mathrm{F}_{\mathrm{IO}_{2}}$ ratio $(165 \pm 16.1)$ at baseline $(P=.08$ and $P<.01$, respectively). Subjects in the failure group also had a lower Glasgow Coma Scale score, higher breathing frequency, higher coronary artery disease history, and higher APACHE II scores. $\mathrm{P}_{\mathrm{aCO}_{2}}$ was not different between groups. The authors concluded that AVAPS may be effective in treating patients with acute hypercapnic respiratory failure due to COPD. They also noted that treatment response in the first $2 \mathrm{~h}$ may indicate NIV effectiveness. These results should be interpreted with caution because this study did not compare AVAPS with standard NIV. It is possible that similar percentages of subjects would have been successful on standard NIV.

Gursel et $\mathrm{al}^{20}$ also evaluated AVAPS in the setting of hypercapnic respiratory failure. They compared AVAPS to a newer mode with auto-titration called AVAPS-AE. While similar to AVAPS, AVAPS-AE also measures upper airway resistance and adjusts EPAP to maintain airway patency. The investigators sought to evaluate the reduction of $\mathrm{P}_{\mathrm{aCO}_{2}}$ and ICU length of stay in subjects treated with these modes. Interestingly, they found that the AVAPS-AE group had a larger decrease in $\mathrm{P}_{\mathrm{aCO}}$, in a shorter amount of time, compared to the AVAPS group $(7 \pm 7 \mathrm{~mm} \mathrm{Hg}$, $2 \pm 5 \mathrm{~mm} \mathrm{Hg}, P=.03$ ). There was no difference in ICU length of stay. The authors concluded that AVAPS-AE offers additional benefits over AVAPS by reducing $\mathrm{P}_{\mathrm{aCO}}$ more rapidly. Although these results are promising, concern remains that adaptive pressure support modes may increase work of breathing when ventilatory support is reduced. Further studies are needed to better understand if adaptive support modes offer any real advantage over standard NIV in the setting of acute respiratory failure.

NAVA uses a diaphragmatic electromyography signal, measured by a specialized nasogastric tube with electrodes placed adjacent to the diaphragm, to control delivery of the breath. ${ }^{22}$ The inspiratory assist from NAVA is proportional to a patient's own breathing efforts. Case reports and clinical investigations have shown that NAVA is effective at improving patient-ventilator synchrony via oronasal and helmet interfaces. ${ }^{1,21-23}$ The specialized NAVA catheter, however, can be cost-prohibitive. ${ }^{1}$ More studies are needed to understand how NAVA can improve patient-ventilator synchrony and impact outcomes such as need for intubation and mortality.

PAV is a mode of ventilation that also generates pressure in proportion to patient effort. ${ }^{21} \mathrm{PAV}$ operates by making calculations regarding resistance, compliance, and work of breathing and adjusts support to a level set by the clinician. ${ }^{21,24}$ Vijayaraghavan et $\mathrm{al}^{24}$ conducted a systematic review and meta-analysis of clinical trials comparing invasive PAV, noninvasive PAV, and PAV + in critically ill subjects. They identified 4 trials that evaluated PAV as an initial mode for NIV. They found that, compared to CPAP, noninvasive PAV did not affect intubation rate in subjects with acute cardiogenic pulmonary edema. They did find that PAV, when compared to pressure support, was reported to be more comfortable, had a lower refusal rate, and had fewer complications. ${ }^{25}$ The authors noted that, although noninvasive PAV may have a positive impact on outcomes like comfort, more research is needed to understand the role of noninvasive PAV in acute respiratory failure. ${ }^{24}$ Due to the overall lack of high-quality clinical trials, PAV cannot be recommended in place of traditional NIV modes in all patients. It appears PAV may be best suited for patients who are intolerant of traditional NIV modes. Further, more studies are needed to determine what impact, if any, leaks may have on adherence and resistance calculations that are used to determine the level of support provided to the patient.

\section{Leak Compensation}

One of the main causes of NIV failure is leak. ${ }^{25}$ Minimizing leak through properly fitting interfaces and compensating for unintentional leak is a high priority for any clinician utilizing NIV. Unfortunately, bi-level and critical care ventilators are not uniform in their ability to properly perform in the presence of leaks. A clinical competency program meant to improve NIV utilization should include a comprehensive review of the devices used to deliver NIV, so that clinicians understand leak compensation capabilities of their devices. 


\section{Trigger/Cycle}

Some devices require clinicians to manually input trigger and cycle criteria. Certain bi-level devices do not require clinicians to adjust these settings because they are auto-adaptive, based on an internal algorithm. Newer devices are generally flow-triggered, which has been reported to improve trigger delays. ${ }^{26}$ Some devices use arbitrary units for trigger sensitivity, which may make identifying proper settings rather difficult. ${ }^{26}$ Although the best way to set trigger sensitivity on NIV is not yet known, it is reasonable to set the device as sensitive as possible without causing auto-triggering (ie, inadvertent triggering of a breath). Clinicians should closely monitor for auto-triggering in the presence of increased leak.

On critical care ventilators, the cycle criteria on pressure support is set as a percentage of peak inspiratory flow. In the presence of a profound leak in pressure support, the cycle criteria may need to be adjusted to a higher percentage to allow the breath to cycle to expiration. Cycling criteria may be auto-adaptive on bi-level ventilators and require no adjustment, but in the presence of a profound leak, auto-adaptive algorithms may fail to cycle the breath to exhalation. If this occurs, a backup safety system will cycle the breath to exhalation after a set time (eg, $3 \mathrm{~s}$ ) at IPAP. The cycle setting on pressure control modes of NIV is the inspiratory time.

\section{Monitoring Capabilities, Portability, Cost, and Familiarity}

Bi-level and critical care ventilators have sophisticated monitoring and alarm functions. These allow clinicians to assess scalar graphics and monitor pressures (high and low), breathing frequency, tidal volumes, and degree of leak. Theoretically, this should improve patient-ventilator synchrony and safety. ${ }^{27}$ These devices can also interface with a hospital's alarms and electronic information systems. While NIV is generally initiated and utilized in emergency departments and ICU environments, it is being increasingly utilized in general wards. ${ }^{28,29}$ The remote monitoring capabilities may allow facilities to utilize NIV on general care wards safely, although this has not been well studied. Until factors that ensure safety during NIV use outside of the emergency department and ICU setting for the treatment of acute respiratory failure are well studied, this practice should be avoided or, at a minimum, done so sparingly.28

Portability of these devices is important because patients frequently require transport while on NIV. Transport could be intra-facility (eg, emergency department to ICU, ICU to radiology, ICU to operating room), to other hospitals, or even to home. Clinicians should be aware that there is significant variability in battery life among bilevel and critical care ventilators. Some devices have in- ternal batteries, while others have internal batteries with optional external batteries available. Battery life may also be shortened significantly when a compressor is in use..$^{30}$

Device cost may influence the use of bi-level or critical care ventilators in the ICU setting. In general, bi-level ventilators cost less than critical care ventilators, although exact numbers to support this statement are difficult to ascertain..$^{4,27}$

Familiarity with the device and its adjuncts, such as mask interfaces and humidifiers, cannot be overstated. Clinicians should be well trained on the use of appropriately sized mask interfaces to avoid leaks, facial skin breakdown, and overall discomfort while utilizing NIV. Humidity may also be helpful to prevent airway dryness when NIV is utilized. Humidity delivered at $100 \%$ relative humidity at $30^{\circ} \mathrm{C}$ is probably sufficient because higher temperatures $\left(37^{\circ} \mathrm{C}\right.$ used in invasive mechanical ventilation) may be intolerable. Further, heat and moisture exchangers are not recommended for use during NIV. ${ }^{1,31}$

\section{Summary}

There are many types of devices capable of delivering NIV in adult acute care. Clinician proficiency with NIV devices is crucial to the successful application of the modality. Clinicians need to be aware of the different terminology, performance characteristics, and capabilities that exist in the devices at their disposal. Clinical training programs for NIV should include specific information about device modes, settings (eg, inspiratory and baseline pressure, trigger/cycle settings, rate, alarms), monitoring capabilities, and portability. More studies are needed to evaluate the performance characteristics and capabilities of newer devices.

\section{REFERENCES}

1. Hess DR. Noninvasive ventilation for acute respiratory failure. Respir Care 2013;58(6):950-972.

2. Cabrini L, Landoni G, Oriani A, Plumari V, Nobile L, Greco M, et al. Noninvasive ventilation and survival in acute care settings: a comprehensive systematic review and metaanalysis of randomized controlled trials. Crit Care Med 2015;43(4):880-888.

3. Scala R, Naldi M. Ventilators for noninvasive ventilation to treat acute respiratory failure. Respir Care 2008;53(8):1054-1080.

4. Chatburn RL. Which ventilators and modes can be used to deliver noninvasive ventilation? Respir Care 2009;54(1):85-101.

5. Williams PF. Noninvasive ventilation. In: Kacmarek RM, Stoller JK, Heuer AJ, editors. Egan's fundamentals of respiratory care, 11th ed. St. Louis, MO: Elsevier; 2017:1111-1135.

6. Hess DR. Noninvasive ventilation and continuous positive airway pressure. In: Hess DR, MacIntyre NR, Galvin WF, Mishoe SC, editors. Respiratory care: principles and practice, 3rd ed. Burlington, MA: Jones and Bartlett Learning; 2016:532-553.

7. Kacmerek RM, Hill NS. Ventilators for noninvasive positive pressure ventilation: technical aspects. Eur Respir Mon 2001;16:76-105.

8. Scott JB, Vines DL. Noninvasive ventilation in the adult. In: Cheifetz I, MacIntyre NR, Marini J, editors. Mechanical ventilation: essentials for current adult and pediatric practice, 1st ed. Mount Prospect, IL: Society of Critical Care Medicine; 2017:199-216. 
9. Fahmy T, Salim S. ICU Ventilators versus BiPAP ventilators in noninvasive ventilation. In: Esquinas AM, editor. Noninvasive mechanical ventilation: theory, equipment, and clinical applications. Berlin: Springer International Publishing; 2015:31-39.

10. Schettino GP, Chatmongkolchart S, Hess DR, Kacmarek RM. Position of exhalation port and mask design affect $\mathrm{CO}_{2}$ rebreathing during noninvasive positive pressure ventilation. Crit Care Med 2003; 31:2178-2182.

11. Olivieri C, Costa R, Conti G, Navalesi P. Bench studies evaluating devices for non-invasive ventilation: critical analysis and future perspectives. Intensive Care Med 2012;38(1):160-167.

12. Vignaux L, Tassaux D, Jolliet P. Performance of noninvasive ventilation modes on ICU ventilators during pressure support: a bench model study. Intensive Care Med 2007;33(8):1444-1451.

13. Ferreira JC, Chipman DW, Hill NS, Kacmarek RM. Bilevel vs ICU ventilators providing noninvasive ventilation: effect of system leaks. Chest 2009;136(2):448-456.

14. Vignaux L, Tassaux D, Carteaux G, Roeseler J, Piquilloud L, Brochard L, et al. Performance of noninvasive ventilation algorithms on ICU ventilators during pressure support: a clinical study. Intensive Care Med 2010;36(12):2053-2059.

15. Carteaux G, Lyazidi A, Cordoba-Izquierdo A, Vignaux L, Jolliet P, Thille AW, et al. Patient-ventilator asynchrony during noninvasive ventilation: a bench and clinical study. Chest 2012;142(2):367.

16. Oto J, Chenelle CT, Marchese AD, Kacmarek RM. A comparison of leak compensation in acute care ventilators during noninvasive and invasive ventilation: a lung model study. Respir Care 2013;58(12):20272037.

17. Nakamura MAM, Costa ELV, Carvalho CRR, Tucci MR. Performance of ICU ventilators during noninvasive ventilation with large leaks in a total face mask: a bench study. J Bras Pneumol 2014; 40(3):294-303.

18. Olivieri C, Costa R, Conti G, Navalesi P. Bench studies evaluating devices for non-invasive ventilation: critical analysis and future perspectives. Intensive Care Med 2012;38(1):160-161.

19. Ciftci F, Ciledag A, Erol S, Oz M, Acar D, Kaya A. Evaluation of the feasibility of average volume-assured pressure support ventilation in the treatment of acute hypercapnic respiratory failure associated with chronic obstructive pulmonary disease: a pilot study. J Crit Care 2017;39:232237.

20. Gursel G, Zerman A, Basarik B, Gonderen K, Aydogdu M, Memmedova S. Noninvasive auto-titrating ventilation (AVAPS-AE) versus average volume-assured pressure support (AVAPS) ventilation in hypercapnic respiratory failure patients. Intern Emerg Med 2018; 13(3):359-365.

21. Kacmarek RM. Proportional assist ventilation and neurally-adjusted ventilatory assist. Respir Care 2011;56(2):140-152.

22. Hadda V, Shah TH, Madan K, Mohan A, Khilnani GC, Guleria R. Noninvasive ventilation-neurally adjusted ventilator assist for management of acute exacerbation of chronic obstructive pulmonary disease. Lung India 2018;35(1):62-65.

23. Sehgal IS, Dhooria S, Aggarwal AN, Behera D, Agarwal R. Asynchrony index in pressure support ventilation (PSV) versus neurally adjusted ventilator assist (NAVA) during non-invasive ventilation (NIV) for respiratory failure: systematic review and meta-analysis. Intensive Care Med 2016;42(11):1813-1815.

24. Tirupakuzhi Vijayaraghavan BK, Hamed S, Jain A, Chimunda T, Telias I, Friedrich JO, et al. Evidence supporting clinical use of proportional assist ventilation: a systematic review and meta-analysis of clinical trials. J Intensive Care Med 2018:885066618769021.

25. De Luca A, Sall FS, Khoury A. Leak compensation algorithms: the key remedy to noninvasive ventilation failure? Respir Care 2017; 62(1):135-136.

26. Rabec C, Rodenstein D, Leger P, Rouault S, Perrin C, GonzalezBermejo $\mathrm{J}$, et al. Ventilator modes and settings during non-invasive ventilation: effects on respiratory events and implications for their identification. Thorax 2011;66(2):170-178.

27. Scala R. Ventilators for noninvasive mechanical ventilation: theory and technology. In: Esquinas AM, editor. Noninvasive mechanical ventilation: theory, equipment, and clinical applications. Berlin: Springer International Publishing; 2015:41-54.

28. Cabrini L, Esquinas A, Pasin L, Nardelli P, Frati E, Pintaudi M, et al. An international survey on noninvasive ventilation use for acute respiratory failure in general non-monitored wards. Respir Care 2015; 60(4):586-592

29. Ozsancak Ugurlu AO, Sidhom SS, Khodabandeh A, Ieong M, Mohr $\mathrm{C}$, Lin DY, et al. Where is noninvasive ventilation actually delivered for acute respiratory failure? Lung 2015;193:779-788.

30. Blakeman TC, Robinson BR, Branson RD. Battery performance of 4 intensive care ventilator models. Respir Care 2010;55(3):317-321.

31. Lellouche F, Pignataro C, Maggiore SM, Girou E, Deye N, Taillé S, et al. Short-term effects of humidification devices on respiratory pattern and arterial blood gases during noninvasive ventilation. Respir Care 2012;57(11):1879-1886.

\section{Discussion}

MacIntyre: I want to return to a topic we got into a little bit yesterday. In your search of the literature, did you ever come across anything that describes the respiratory assist device, or so-called RAD?

Scott: I will be honest with you, yesterday was the first time I heard the term RAD.

\section{MacIntyre: I rest my case!}

Davies: One of the problems that we have in our institution is that, if we extubate a COPD patient to NIV in the ICU on a critical care ventilator, they subsequently get transferred to the step-down unit where our ventilator of choice is the V60. Now inspiratory pressure is referenced to atmosphere (as opposed to PEEP on the critical care ventilator), and that same inspiratory pressure results in a smaller distending pressure. I don't know how many times I've heard, "Hey, we've transferred this patient out and they' re having some trouble," and that's the reason - the same settings resulted in a decreased distending pressure. My question is, other than the Dräger, where when you turn it on auto-flow it references the inspiratory pressure to atmosphere, are there other critical care ventilators that have the ability to reference inspiratory pressure to atmosphere?

Scott: The Dräger is the only critical care ventilator that I am aware of that does that. In terms of the inspiratory pressure, the Dräger is very similar to the V60, but devices like the PB840 or PB980 are much different. A $10 / 5 \mathrm{~cm} \mathrm{H}_{2} \mathrm{O}$ in one device is definitely not $10 / 5 \mathrm{~cm} \mathrm{H}_{2} \mathrm{O}$ in the other device. I don't think it really matters which device you have, as long as you understand the differences between them. 
Piraino: It's even more complicated than that. With the Dräger, for example, if you're using pressure support in NIV mode, it's delta pressure above PEEP. But if you're using one of the control modes with a set breathing frequency, it's now the inspiratory pressure, which is similar to IPAP.

Scott: Over the years, I have been privileged to teach a lot of folks NIV and I have found that very few people are aware of issues such as this. Honestly, they are often surprised by it. I think this is one of the limitations we have in having so much variability between devices; people just don't know how devices perform.

Hill: Brady [Scott], great job first of all. I can tell you put a lot of time and effort into this. Having fiddled around in this field for a while now, I would consider what you've seen since you started in 2007 as the modern era. But this goes back decades before that, and it is remarkable how far we've come. The first BPAP (bi-level positive airway pressure) device, although it actually worked probably as well as the AVAPS-AE (average volume-assured pressure support with auto-expiratory positive airway pressure) mode you showed us, was a timed mode without any patient-triggering capabilities.

Scott: Time-triggered or cycled?

Hill: It was both, so basically a pressure control mode. But anyway, the original BPAP in response to leak would go on 3-s inspiratory and would then automatically cycle back to expiratory, so you'd find patients who were getting $3 \mathrm{~s}$ of inspiratory, and a microsecond of expiratory, and then another $3 \mathrm{~s}$ of inspiratory. They would still get ventilated somewhat.

Scott: Sounds like noninvasive APRV (airway pressure release ventilation).
Hill: Exactly, it was noninvasive APRV. Obviously the modern devices do much, much better, and the algorithms today are incredible in how well they match patient effort even in the face of substantial leak, which has been such a huge challenge to synchrony in NIV. They really have come a long way. Now we have this vast array of different approaches, and the terminology differences are very confusing; we have bells and whistles that may or may not be very meaningful. I think it's really important for us to keep our goals in mind-what are we trying to achieve with NIV? Usually there's a physiological target; pressure support modes during NIV are adjusted to a target patient breathing frequency and tidal volume. Achieving good synchrony and gas exchange targets are goals, too. But with NIV, subjective responses like alleviation of respiratory distress and achieving tolerance are particularly important goals. I think prioritizing goals is really important, and it's hard to get at that in these bench studies. Ventilating patients safely is also on the list. In this context, a lot of the changes and new modes that we've seen on NIV ventilators have not been shown to achieve goals better than earlier devices. If something lowers the $\mathrm{CO}_{2}$ a little faster-say, lowering it more than a comparator device at $30 \mathrm{~min}$ but not at 60 min-it probably doesn't mean anything. However, we do have to be concerned about the human aspect, too. A problem I've run into over the years is that we need human intervention to optimize the settings after initiating NIV, and it often doesn't happen. I think that's where some of these automatic modes have an advantage; they can make sure that you're achieving certain targets rather than have to rely on humans to come back and make further adjustments.

Scott: I think one of the underappreciated advantages of some of the NIV ventilators that are available to- day are the blenders that allow us to give $\mathrm{O}_{2}$ the way we want to, versus the bleed-in systems of the original generation.

Hill: That's a good point, I agree entirely.

Scott: You couldn't use it on somebody in hypoxemic respiratory failure because we couldn't get the $\mathrm{F}_{\mathrm{IO}_{2}}$ that was needed. Now we have the ability to provide $100 \%$ oxygen and have these very nice leak compensation and trigger abilities that, in some cases, don't even require adjustments by the clinicians.

Hill: Right, it was really the Vision that brought that.

Scott: It was a game-changer.

Davies: You commented on a couple of new modes. Proportional assist ventilation (PAV) for starters-my experience is that you can't use it with NIV because leaks will interfere with its algorithm. So I was interested to hear about that study. Were they able to use it with NIV successfully on the PB840 or PB980?

Scott: The version that I'm most familiar with is on the V60, it's called PPV (proportional pressure ventilation). I'm assuming that's the closest to PAV, or a similar concept?

Davies: Yes, my understanding is that it is a different algorithm.

Hill: It's the pressure-limited version of PAV, and it is proprietary to Respironics. Dean Hess, Peter Gay, and I did a study ${ }^{1}$ on that and it actually works great with NIV. The algorithm handles leaks similar to the way that it does with standard BPAP and it wasn't a problem. The earlier PAV, the version that Magdy Younes first developed, had some issues with that and probably wouldn't have worked 
with NIV very well. It had the "runaway phenomenon" where pressure and flow would rise excessively in response to leak. But there were subsequent algorithms built in to take care of that. The study we did compared it to the 7200 as insisted upon by the FDA. The PAV mode proved to be more comfortable than pressure support on the 7200 , but of course that was a low bar. The PAV mode worked well then and continues to work well for NIV. However, does it work demonstrably better than a sophisticated, properly adjusted pressure support mode, especially with regard to outcomes like avoidance of intubation, rapidity of weaning or length of stay? Probably not.

Davies: This is one of my concerns: PPV and PAV operate very similarly, but as Nick [Hill] was saying their limitations are very different. You mentioned a new neurally-adjusted ventilatory assist (NAVA) mode, and maybe I wasn't paying complete attention, but is that like AVAPS in NAVA?

Piraino: What they're doing there is still NAVA, but limiting the pressure. They are using a significantly high gain $\left(15 \mathrm{~cm} \mathrm{H}_{2} \mathrm{O}\right.$ per $\mathrm{EA}_{\mathrm{di}}$ [electrical activity of the diaphragm]), and then using an upper pressure limit so it limits the pressure similar to setting a pressure support level but still uses the synchrony of the NAVA in order to deliver the breath. ${ }^{2}$

Davies: Does the ventilator automatically adjust the NAVA level?

Piraino: No, you set the pressure support level, where it's going to reach that pressure but it's going to reach it with the synchrony of NAVA. In terms of how quickly, the rise time, for example, would be based on the patient's $\mathrm{EA}_{\mathrm{di}}$ and the synchrony, but it's basically pressure support because you're cranking it so high that the pressure is actually what limits it.
Scott: AVAPS is different because it uses tidal volume as feedback in order to change the settings.

Piraino: The study refers to it as a new setting of NAVA, but it's not a new mode on a ventilator.

Strickland: If I could, I'd like to turn our attention back to the respiratory therapist (RT) who is likely the person setting this up in the acute care setting. One of the things that stood out as you were going through these different machines, typically we're going to place a patient on NIV postextubation and we have ICU ventilators that have an NIV mode. Due to ease, cost of circuitry, timing, and so forth, we're going to use the NIV mode on the invasive ventilator because it's at the bedside. If the patient fails, I don't have to get a new machine, and so on. So, we have the RT who needs to understand the capabilities of the ICU ventilator in NIV mode and the mask; we talked yesterday at length about how RTs and other practitioners are not fitting the mask appropriately. You had a fairly amazing picture of a patient on an NIV mask that was not effective at all, so there's that issue. We have different parameters on different machines, and what does this particular machine mean versus that one, and then we have the human perspective of I have a patient on an ICU ventilator with an NIV mask of some sort, and then we're moving them to another area of the hospital. And maybe that's when we move them to a different ventilator with different parameters that mean different things, and now the family is seeing that different machine. In my experiences with infants on an NIV mode on an ICU ventilator, we would remove that ventilator because it's expensive and it has bells and whistles I can use on another patient, right? So I'm going to give them an NIV ventilator because it's made for that, and the family throws a fit because now their loved one is not getting the same level of care (they perceive) because it's a different ventilator. I say all of that to bring it back to the nuances that the practitioner has to account for within transitioning a patient from an endotracheal tube, to NIV, to a true NIVonly system as they step down in the hospital, and then as we're trying to transition them home they're likely to have even another ventilator to get them home. No real question here, just identifying all the different layers of this application that primarily the RT has to deal with as they go through, which of course impacts how we teach our RTs, physicians, nurses, and other clinicians about the modes.

* Jackson: Brady, I just want to add one comment to that. I think that there is one other complicating factor with all this information that you provided us. How do we possibly keep the RTs, who are the ones responsible, trained and competent on all of the equipment, especially when you may have 2 or 3 different ICU ventilators in some hospitals, you have NIV ventilators, and you have intermediate ones? It becomes very complex to keep everybody up to date on competency with this stuff, especially when manufacturers use different names for the same mode, but the idea or the theory behind the process is the same but they change the name and you have to readjust everybody to that again.

Scott: On one hand, the improved technology probably increases our chance of better patient-ventilator synchrony and improves patient care. On the other hand, there is at least a theoretical patient safety issue because it's just a lot for us to keep up with. Hospital competency programs have to focus on the nuanced differences between these devices. And I'll say it here, I think physicians need to be brought in on this as well. Because if

\footnotetext{
* Julie A Jackson RRT RRT-ACCS, invited discussant, Fisher \& Paykel.
} 
they're writing orders or they need to understand how a patient is responding to NIV, they need to know that, to use the earlier example, $10 / 5 \mathrm{~cm} \mathrm{H}_{2} \mathrm{O}$ on one machine might not be $10 / 5 \mathrm{~cm}$ $\mathrm{H}_{2} \mathrm{O}$ on another.

Benditt: Thank you for a great presentation. Neil [MacIntyre] was joking about RAD versus ventilator definition, but the application of these different modes have a dramatic impact on what you send the patient home with because certain modes are only available on certain devices that are classified as a ventilator versus a RAD. So the unfortunate thing is there are a lot of different things happening, modes and devices and all that. But out in the trenches it has a gigantic impact. I'm of the mindset that simpler is better and that, unless a certain mode of application has been shown to have better results, I stick with the basics, and I feel much more comfortable that the patient is going to get what I order and it will be paid for appropriately.

Scott: I remember yesterday you said a lot of your NMD (neuromuscular disease) patients you do not use AVAPS, you send them home on bilevel ventilation with settings. Right?

Benditt: Yes. The question of AVAPS and particularly AVAPS-AE has come up in NMD, obesity, and hypoventilation patients, and at this point I am not aware of any papers that show a benefit of the more complex mode for these patients. In my own experience, a lot of times AVAPS, unless it's set up perfectly, wakes the patient up a lot at night because they sense the pressures going up as it adjusts. So I have not been a big fan of it, and I haven't seen any data that it works well at this point.

\section{REFERENCES}

1. Gay PC, Hess DR, Hill NS. Noninvasive proportional assist ventilation for acute respiratory insufficiency. Comparison with pressure support ventilation. Am J Respir Crit Care Med 2001;164(9):1606-1611.

2. Longhini F, Pan C, Xie J, Cammarota G, Bruni A, Garofalo E, et al. New setting of neurally adjusted ventilatory assist for noninvasive ventilation by facial mask: a physiologic study. Crit Care 2017;21(1):1-9. 